\title{
The variations of body mass index and body fat in adult Thai people across the age spectrum measured by bioelectrical impedance analysis
}

This article was published in the following Dove Press journal:

Clinical Interventions in Aging

I4 November 201 I

Number of times this article has been viewed

\section{Kaweesak \\ Chittawatanarat ${ }^{1,2}$ \\ Sakda Pruenglampoo ${ }^{3}$ \\ Siriphan Kongsawasdi ${ }^{4}$ \\ Busaba Chuatrakoon ${ }^{4}$ \\ Vibul Trakulhoon ${ }^{5}$ \\ Winai Ungpinitpong ${ }^{6}$ \\ Jayanton Patumanond ${ }^{2}$ \\ 'Department of Surgery, Faculty of Medicine, ${ }^{2}$ Clinical Epidemiology Unit, ${ }^{3}$ Research Institute for Health Sciences, ${ }^{4}$ Department of Physical Therapy, Faculty of Associated Medical Sciences, Chiang Mai University, Chiang Mai, ${ }^{5}$ Department of Surgery, Bhumibol Adulyadej Hospital, Bangkok, ${ }^{6}$ Surgical Unit, Surin Hospital, Surin, Thailand}

\section{Video abstract}

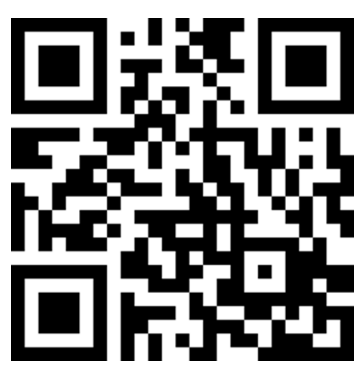

Point your SmartPhone at the code above. If you have a OR code reader the video abstract will appear. Or use: http://dvpr.es/p20WI

Correspondence: Kaweesak Chittawatanarat

Department of Surgery, Faculty of Medicine, Maharaj Nakorn Chiang Mai

Hospital, Chiang Mai University, Amphur

Muang, Chiang Mai, Thailand 50200

Tel +6653945533

Fax +66 53946139

Email kchittaw@gmail.com
Background: The measurements of body mass index (BMI) and percentage of body fat are used in many clinical situations. However, special tools are required to measure body fat. Many formulas are proposed for estimation but these use constant coefficients of age. Age spectrum might affect the predicted value of the body composition due to body component alterations, and the coefficient of age for body fat prediction might produce inconsistent results. The objective of this study was to identify variations of BMI and body fat across the age spectrum as well as compare results between BMI predicted body fat and bioelectrical impedance results on age.

Methods: Healthy volunteers were recruited for this study. Body fat was measured by bioelectrical impedance. The age spectrum was divided into three groups (younger: 18-39.9; middle: 40-59.9; and older: $\geq 60$ years). Comparison of body composition covariates including fat mass (FM), fat free mass (FFM), percentage FM (PFM), percentage FFM (PFFM), FM index (FMI) and FFM index (FFMI) in each weight status and age spectrum were analyzed. Multivariable linear regression coefficients were calculated. Coefficient alterations among age groups were tested to confirm the effect of the age spectrum on body composition covariates. Measured PFM and calculated PFM from previous formulas were compared in each quarter of the age spectrum.

Results: A total of 2324 volunteers were included in this study. The overall body composition and weight status, average body weight, height, BMI, FM, FFM, and its derivatives were significantly different among age groups. The coefficient of age altered the PFM differently between younger, middle, and older groups $(0.07 ; P=0.02$ vs $0.13 ; P<0.01$ vs $0.26 ; P<0.01$; respectively). All coefficients of age alterations in all FM- and FFM-derived variables between each age spectrum were tested, demonstrating a significant difference between the younger ( $<60$ years) and older ( $\geq 60$ years) age groups, except the PFFM to BMI ratio (difference of PFM and FMI [95\% confidence interval]: 17.8 [12.8-22.8], $P<0.01$; and 4.58 [3.4-5.8], $P<0.01$; respectively). The comparison between measured PFM and calculated PFM demonstrated a significant difference with increments of age.

Conclusion: The relationship between body FM and BMI varies on the age spectrum. A calculated formula in older people might be distorted with the utilization of constant coefficients.

Keywords: fat mass, fat free mass, age, body mass index, Thai

\section{Introduction}

Body mass index (BMI) is widely used for nutritional assessment, obesity classification, and as a prognostic variable for mortality. ${ }^{1}$ However, there are many limitations. First, the BMI could potentially produce an inaccurate diagnosis of "overweight" and "obese" in some special populations such as athletes, body builders, and elderly patients. ${ }^{2-4}$ Second, BMI-associated mortality in specific situations is controversial. ${ }^{1,5,6}$ A large 
retrospective study in critically ill patients demonstrated that only underweight was associated with poor outcomes in contrast with overweight and obesity. ${ }^{7}$ These results are similar to a large prospective study of nonbariatric surgical patients. ${ }^{8}$ This difference might be explained by the fat mass (FM) and fat free mass (FFM) proportions in the patients. The decrease of FFM and increase of FM had a negative impact on the overall mortality in an epidemiologic study, especially in males. ${ }^{5,6}$ Therefore, the combination of BMI and FM might be useful as a clinical prognostic indicator as well as diagnostic criterion for obesity. However, the percentage of FM (PFM) could be predicted with a variety of formulas using BMI, gender, ethnic differences, and age. All of these generate a model based on linear assumption with constant individual variable coefficients. ${ }^{9,10}$ Although ethnic and gender differences have a proven effect on the relationship between FM and BMI, these have not been analyzed in relation to the age spectrum. ${ }^{4,11,12}$ The authors, however, suspected that age spectrum might distort this relationship and the coefficient of age might be inconsistent throughout the life span as opposed to gender and race. Therefore, the objectives of this study were to demonstrate the alteration and variation of the relationship between FM and its derivatives and BMI over each age group in the same ethnicity, and to compare this study's measured FM with previously estimated formulas.

\section{Materials and methods}

The authors enrolled healthy Thai volunteers by way of invitation at the Faculty of Medicine, Chiang Mai University, between May 2010 and May 2011. Volunteers were people from the general community. Four research assistants were trained in the measurement of bioelectrical impedance analysis (BIA). Body weight was measured using the same digital weighing apparatus each time (TCA-200 A-RT; Zepper, Bangkok, Thailand) and recorded in kilograms to one decimal point. Height was measured using a standard measuring board; the subjects' body positions ensured their head, shoulder blades, buttocks, and heels were touching the board during measurement. Height was recorded in centimeters. BMI was calculated by dividing the body weight in kilograms by square height in meters (BMI = body weight $[\mathrm{kg}] /$ height $\left.\left[\mathrm{m}^{2}\right]\right)$. Volunteers who exhibited any characteristics that might interfere with measured parameters were excluded. These included: subjects $<18$ years old; pregnant women; persons with any implanted electronic device; those exhibiting signs of chronic steroid use; persons with amputated limb(s), or limited ambulation, inability to lie down, or edematous limb(s); and those with chronic diseases such as liver cirrhosis, renal failure, and heart failure. This study was approved by the Faculty of Medicine, Chiang Mai University Ethics Committee. All volunteers gave informed consent before their enrollment into the study.

A bioelectrical impedance analyzer (Biodynamics BIA 310 $\mathrm{e}^{\mathrm{TM}}$; Biodynamics Corporation, Seattle, WA) was used to analyze body composition. This machine is a single frequency BIA (SF-BIA) that generates a $50 \mathrm{kHz}$ current, which passes between surface electrodes placed on the hand and foot. ${ }^{13}$ The machine's sensor measures the reactance and resistance range up to 300 and 1500 Ohms, respectively. Input data were calculated using the machine's software and output was reported as PFM, percentage of FFM (PFFM), FM, FFM, and total body water. The machine was always tested by two research assistants to verify accuracy before use. One assistant tested the machine by measuring the BIA results of the other assistant at least twice. The result was considered valid if it did not have an error $>5 \%$. Fat mass index (FMI) and fat free mass index (FFMI) were calculated by dividing the fat mass and fat free mass by square height in meters (ie, FMI $=\mathrm{FM} /$ height $^{2}\left[\mathrm{~m}^{2}\right]$; FFMI $=\mathrm{FFM} /$ height $\left.{ }^{2}\left[\mathrm{~m}^{2}\right]\right)$.

Because single frequency bioelectrical impedance analysis is not valid under conditions of significantly altered hydration, ${ }^{14}$ before analysis all volunteers were asked to observe the following pretest guidelines: (1) no alcohol consumption within 24 hours; (2) no exercise, caffeine, or food within 4 hours prior to taking the test, (3) drink two to four glasses of water 2 hours before examination. During the examination, two pairs of sensor electrocardiograph pads were placed on the patient, one on the right wrist and hand and the other on the right foot and ankle. At least $75 \%$ of the electrode was required to be in contact with the patient's skin. Patient data, including gender, age, height, and weight, were entered into the machine's software before each test. Results of the measurements were recorded and printed.

\section{Comparison of percentage body fat with other fat prediction formulas}

The predicted percentage of fat by sex, BMI, and age was calculated using the formulas proposed by Gallagher et al. ${ }^{9}$ These formulas were selected for three reasons. First, the formulas were generated based on two standard measurements: dual energy X-ray absorptiometry (DXA) and the four compartment model (4C). Second, the formulas considered ethnic differences and integrated ethnic parameters. Finally, the formulas considered the interaction among the 
parameters involved. The equations were demonstrated as follows: ${ }^{9}$

1. DXA model: $\mathrm{PFM}=76.0-1097.8\left(\mathrm{BMI}^{-1}\right)-20.6$ $(\mathrm{Sex})+0.053($ Age $)+95.0($ Asian $)\left(\mathrm{BMI}^{-1}\right)-0.044$ $($ Asian $)($ Age $)+154(\mathrm{Sex})\left(\mathrm{BMI}^{-1}\right)+0.034(\mathrm{Sex})($ Age $)$

2. $4 \mathrm{C}$ model: $\mathrm{PFM}=63.7-864\left(\mathrm{BMI}^{-1}\right)-12.1(\mathrm{Sex})+0.12$ $($ Age $)+129($ Asian $)\left(\mathrm{BMI}^{-1}\right)-0.091($ Asian $)($ Age $)+0.03$ (African American) (Age)

These formulas reported a correlation coefficient of about 0.90 and standard error of estimation of about $4 \%$. Variables were defined as sex $=1$ for male and 0 for female; Asian $=1$ for Asian and 0 for other races. ${ }^{9}$

\section{Statistical analysis}

Volunteers were categorized according to age into three groups: younger (18-39 years), middle (40-59 years), and older ( $\geq 60$ years). Each group was further divided into four, using 5-year intervals - except in the first group, which ranged from 18 to 24 years, and the last group, which began at $\geq 75$ years. Weight status was based on BMI using the World Health Organization diagnostic criteria and categorized into four groups: underweight $\left(<18.5 \mathrm{~kg} / \mathrm{m}^{2}\right)$, normal (18.5-24.9 kg/m²), overweight (25-29.5 kg/m²), and obese $\left(\geq 30 \mathrm{~kg} / \mathrm{m}^{2}\right) .{ }^{15}$

Differences among the groups were tested depending on data types. Categorized data were tested by chi square. All of the continuous variable data were reported as mean \pm standard deviation. The difference among age groups was tested for equal variances using Bartlett's test and Bonferroni comparison. Group differences were calculated using one-way analysis of variance test for equal variance and the Kruskal-Wallis test for unequal variance. A comparison was made between PFMs to verify the previously used Gallagher et al formulas, ${ }^{9}$ and paired Student's $t$-test was calculated to demonstrate differences in each quartile of each age group. A Bland-Altman plot was performed to demonstrate the error between the predicted PFM formula and the measured PFM for age.

A multivariate regression model was used to test the association between the PFM and independent variables (age, gender, BMI, and status). Weight status was categorized by BMI criteria as previous mentioned and was adjusted for gender and age. The coefficient of age spectrum in older volunteers ( $\geq 60$ years) was compared with younger ( $<60$ years) by multivariate linear regression, and the interaction between age and age spectrum was tested. Data were analyzed by STATA (v 11.0; STATA Inc, College Station, TX) software. A statistically significant difference was defined as a $P$ value of $<0.05$.

\section{Results}

During this 13-month study, 2324 volunteers (1324 females and 1000 males) were included. The number of females was slightly higher in this study (female 57\%; male 43\%). The most common three occupations were worker, farmer, and officer, with different proportions in each age group. Ninety-six percent of the study population resides in the northern region of Thailand (Table 1). Body weight, height, and BMI were significantly different between age groups and gender. Nearly $60 \%$ of the population had a normal weight status. Approximately one quarter of the study population was overweight ( $24 \%$ of females and $26.8 \%$ of males) and $<10 \%$ were underweight or obese (Table 1). Although the overall proportion of weight status between genders was comparable, there was a higher percentage of obesity in females in the older age group (Table 1).

Using a BIA to analyze body fat and FFM as shown in Table 2, the volunteers of both genders had significant differences $(P<0.05)$ between younger, middle, and older age groups of FM, FFM, PFM, PFFM, FMI, FFMI, PFMR (percentage fat mass ratio $=$ PFM:BMI), and PFFMR (percentage fat free mass ratio = PFFM:BMI). However, after subgroup analysis by weight status and gender, differences could be observed in two groups. First, in the under, normal, and overweight status groups there were significant differences between age groups of both genders for all previous parameters mentioned except FM. In the overweight group a significant difference in FM and PFFMR was found only among females in the underweight volunteers. Second, in the obese group, no parameter had significant differences for either gender, but all parameters except for FM and PFFMR were statistically different among the females. The relationships between the PFM, PFFM, BMI PFMR, and PFFMR over the age spectrum in each gender are shown in Figures 1 and 2. These figures show that PFM and BMI initially increased in parallel with age, diverged at middle age, and separated significantly for those aged $>60$ years, while the percentage of FFM decreased (Figure 1). These findings corresponded that the PFMR remained steady over time until 50 years of age when it increased in both genders, while the PFFMR was rather stable into older ages (Figure 2).

Multivariate regression coefficients adjusted for age, gender, BMI, and weight status of PFM are shown in Table 3. Of these, all of the parameters had significantly different coefficients in each age group except in the underweight volunteers. The females had higher body fat than males, by approximately $7.44 \%$, which lowered in the middle age 
Table I Demographic data of volunteers in each age group

\begin{tabular}{|c|c|c|c|c|c|}
\hline Parameters & $\begin{array}{l}\text { Younger } \\
(n=459)\end{array}$ & $\begin{array}{l}\text { Middle } \\
(n=862)\end{array}$ & $\begin{array}{l}\text { Older } \\
(n=1003)\end{array}$ & $\begin{array}{l}\text { Total } \\
(n=2324)\end{array}$ & $P$ value \\
\hline Gender (\%) & & & & & $<0.01$ \\
\hline Female & $311(67.8)$ & $510(59.2)$ & $503(50.2)$ & I $324(57.0)$ & \\
\hline Male & I48 (32.2) & $352(40.8)$ & $500(49.8)$ & $1000(43.0)$ & \\
\hline Occupation (\%) & & & & & $<0.01$ \\
\hline Farmer & $33(7.2)$ & $|8|(2 \mid .0)$ & $169(16.8)$ & $383(16.5)$ & \\
\hline Officer ${ }^{\dagger}$ & $52(11.3)$ & $145(16.8)$ & $157(15.6)$ & $354(15.2)$ & \\
\hline Private & $55(12.0)$ & $150(17.4)$ & $61(6.1)$ & $266(11.5)$ & \\
\hline Worker & $174(37.9)$ & $239(27.7)$ & $88(8.8)$ & $501(21.6)$ & \\
\hline Unemployed & $110(24.0)$ & $79(9.2)$ & $59(5.9)$ & $248(10.7)$ & \\
\hline Other & $35(7.6)$ & $68(7.9)$ & $469(46.8)$ & $572(24.6)$ & \\
\hline Habitats (\%) & & & & & 0.55 \\
\hline Northern & $437(95.2)$ & $827(96.0)$ & $967(96.4)$ & 2231 (96) & \\
\hline Other & $22(4.8)$ & $35(4.0)$ & $36(3.6)$ & $93(4.0)$ & \\
\hline \multicolumn{6}{|c|}{ Body weight (kg) } \\
\hline Female & $56.5 \pm 10.7$ & $57.9 \pm 10.0$ & $54.3 \pm 10.9$ & $56.2 \pm 10.6$ & $<0.01$ \\
\hline Male & $67.3 \pm 12.7$ & $68.0 \pm 12.1$ & $59.7 \pm 11.0$ & $63.7 \pm 12.3$ & $<0.01$ \\
\hline \multicolumn{6}{|l|}{ Height $(\mathbf{c m})^{\ddagger}$} \\
\hline Female & $156.3 \pm 5.7$ & $154.3 \pm 5.3$ & $151.9 \pm 6.5$ & $153.9 \pm 6.1$ & $<0.01$ \\
\hline Male & $167.5 \pm 6.6$ & $165.5 \pm 5.7$ & $162.1 \pm 7.2$ & $164.1 \pm 6.9$ & $<0.01$ \\
\hline \multicolumn{6}{|l|}{ BMI $\left(\mathbf{k g} / \mathrm{m}^{2}\right)^{\ddagger}$} \\
\hline Female & $23.1 \pm 4.2$ & $24.3 \pm 3.8$ & $23.5 \pm 4.1$ & $23.7 \pm 4.1$ & $<0.01$ \\
\hline Male & $23.9 \pm 4.1$ & $24.8 \pm 4.0$ & $22.6 \pm 3.4$ & $23.6 \pm 3.9$ & $<0.01$ \\
\hline \multicolumn{6}{|l|}{ Status (\%) } \\
\hline Female & & & & & $<0.01$ \\
\hline Underweight & $29(9.3)$ & $15(2.9)$ & $54(10.7)$ & $98(7.4)$ & \\
\hline Normal & $206(66.2)$ & $311(61.0)$ & $294(58.5)$ & $811(61.3)$ & \\
\hline Overweight & $53(17.0)$ & $152(29.8)$ & $113(22.3)$ & $318(24.0)$ & \\
\hline Obese & $23(7.4)$ & $32(6.3)$ & $42(8.4)$ & $97(7.3)$ & \\
\hline Male & & & & & $<0.01$ \\
\hline Underweight & $10(6.8)$ & $10(2.8)$ & $47(9.4)$ & $67(6.7)$ & \\
\hline Normal & $84(56.8)$ & $189(53.7)$ & $345(69.0)$ & $618(61.8)$ & \\
\hline Overweight & $42(28.4)$ & $130(36.9)$ & $96(19.2)$ & $268(26.8)$ & \\
\hline Obese & $12(8.1)$ & $23(6.5)$ & $12(2.4)$ & $47(4.7)$ & \\
\hline
\end{tabular}

Notes: ${ }^{\dagger}$ Includes retired officers; ${ }^{\ddagger}$ mean \pm standard deviation.

Abbreviation: BMI, body mass index.

group. The coefficient of BMI was 0.5, which was highest in middle age $(0.66 ; P<0.01)$ but lowest in older age $(0.42$; $P<0.01)$. The relationship between increasing age and body composition showed an orderly increase of PFM over each additional year of aging $(0.07 \%, 0.13 \%$, and $0.26 \%$ in the younger, middle, and older groups, respectively). PFM changes in underweight, overweight, and obese groups (compared with normal weight status) had the highest alteration in middle age and the lowest in the older age - except in the underweight category, which was comparable to the younger group (Table 3).

To confirm the coefficient alteration of age spectrums on all FM and FFM variables, the authors compared the age spectrum effects between older age volunteers ( $\geq 60$ years) and younger ages ( $<60$ years) based on the previously mentioned findings and Figures 1 and 2. The results are shown in Table 4. Of these, PFM, PFFM, FMI, and FFMI had significant differences in coefficient alteration among age spectrums $(P<0.01)$. However, there were no differences in coefficient change between groups in PFFMR $(P=0.11)$.

To demonstrate how the age spectrum affected the validity of PFM prediction, the authors compared PFM between measured PFM by BIA and calculated $\mathrm{PFM}^{9}$ on each age spectrum (Figure 3) as well as error of PFM between BIA measurements and calculated PFM (Figure 4). ${ }^{9}$ BIA measured as PFM was comparable only in the age range of 30 and 45 years. Differences started at $45-50$ years $(P<0.01)$ and showed significance after that age $(P<0.001)$. Errors of PFM prediction from BMI-based formulas using four compartments and the DXA model were demonstrated using the Bland-Altman 
Table 2 Mean and standard deviation of weight, percentage, and ratio to BMI of fat mass and lean body mass in each age group and status

\begin{tabular}{|c|c|c|c|c|c|c|c|c|}
\hline & \multicolumn{2}{|l|}{ Younger } & \multicolumn{2}{|l|}{ Middle } & \multicolumn{2}{|l|}{ Older } & \multicolumn{2}{|l|}{ Total } \\
\hline & Female & Male & Female & Male & Female & Male & Female & Male \\
\hline \multicolumn{9}{|l|}{$\mathrm{FM}(\mathrm{kg})$} \\
\hline Overall** & $18.1 \pm 5.4$ & $16.4 \pm 5.5$ & $19.8 \pm 5.8$ & $18.4 \pm 6.0$ & $20.1 \pm 5.8$ & $|7.5 \pm 5|$. & $19.5 \pm 5.7$ & $17.7 \pm 5.5$ \\
\hline Underweight* & $12.1 \pm 2.5$ & $10.1 \pm 2.6$ & $12.4 \pm 2.5$ & $11.5 \pm 3.7$ & $13.6 \pm 2.6$ & $12.7 \pm 3.6$ & $13.0 \pm 2.7$ & $12.1 \pm 3.6$ \\
\hline Normal** & $16.4 \pm 2.9$ & $13.9 \pm 3.0$ & $17.1 \pm 3.0$ & $15.7 \pm 3.2$ & $18.4 \pm 3.3$ & $16.7 \pm 3.9$ & $17.4 \pm 3.2$ & $16.0 \pm 3.7$ \\
\hline Overweight & $22.8 \pm 3.3$ & $19.7 \pm 3.4$ & $23.3 \pm 3.3$ & $21.0 \pm 3.5$ & $23.6 \pm 3.4$ & $21.1 \pm 3.8$ & $23.3 \pm 3.3$ & $20.8 \pm 3.6$ \\
\hline Obese & $29.5 \pm 6.1$ & $28.2 \pm 4.3$ & $32.3 \pm 8.8$ & $29.1 \pm 12.8$ & $31.3 \pm 7.4$ & $29.3 \pm 11.3$ & $32.2 \pm 7.6$ & $28.9 \pm 10.7$ \\
\hline \multicolumn{9}{|l|}{ FFM (kg) } \\
\hline Overall** & $38.5 \pm 6.3$ & $50.8 \pm 8.3$ & $38.1 \pm 5.5$ & $49.6 \pm 7.8$ & $34.2 \pm 6.8$ & $42.2 \pm 8.6$ & $36.7 \pm 6.5$ & $46.1 \pm 9.2$ \\
\hline Underweight** & $30.1 \pm 5.1$ & $39.6 \pm 3.9$ & $29.6 \pm 3.0$ & $36.4 \pm 6.0$ & $25.5 \pm 4.8$ & $31.1 \pm 6.0$ & $27.5 \pm 5.1$ & $33.2 \pm 6.5$ \\
\hline Normal** & $37.1 \pm 4.1$ & $47.7 \pm 5.6$ & $36.2 \pm 4.1$ & $46.3 \pm 5.4$ & $32.7 \pm 5.0$ & $41.0 \pm 6.5$ & $35.2 \pm 4.8$ & $43.6 \pm 6.7$ \\
\hline Overweight** & $43.3 \pm 4.2$ & $55.7 \pm 5.9$ & $40.9 \pm 4.0$ & $53.2 \pm 6.0$ & $38.9 \pm 5.5$ & $50.0 \pm 7.7$ & $40.6 \pm 4.8$ & $52.4 \pm 6.9$ \\
\hline Obese* & $50.0 \pm 5.3$ & $64.7 \pm 7.1$ & $47.0 \pm 7.1$ & $62.0 \pm 9.7$ & $43.0 \pm 5.3$ & $57.7 \pm 6.1$ & $46.0 \pm 6.5$ & $61.6 \pm 8.5$ \\
\hline \multicolumn{9}{|l|}{ PFM(\%) } \\
\hline Overall** & $31.6 \pm 4.7$ & $24.0 \pm 4.5$ & $33.7 \pm 5.0$ & $26.8 \pm 5.0$ & $36.9 \pm 5.9$ & $29.4 \pm 6.6$ & $34.4 \pm 5.7$ & $27.7 \pm 6.1$ \\
\hline Underweight** & $28.9 \pm 6.6$ & $20.4 \pm 5.4$ & $29.5 \pm 5.2$ & $24.4 \pm 8.7$ & $35.1 \pm 7.3$ & $29.3 \pm 8.8$ & $32.4 \pm 7.4$ & $27.2 \pm 8.9$ \\
\hline Normal** & $30.6 \pm 3.7$ & $22.5 \pm 3.6$ & $32.0 \pm 4.4$ & $25.3 \pm 4.5$ & $36.0 \pm 5.6$ & $29.1 \pm 6.3$ & $33.1 \pm 5.2$ & $27.0 \pm 6.0$ \\
\hline Overweight** & $34.4 \pm 3.8$ & $26.1 \pm 3.6$ & $36.2 \pm 3.8$ & $28.3 \pm 4.4$ & $37.9 \pm 4.8$ & $30.0 \pm 6.0$ & $36.5 \pm 4.3$ & $28.6 \pm 5.1$ \\
\hline Obese* & $36.9 \pm 4.9$ & $30.3 \pm 3.1$ & $40.5 \pm 3.9$ & $31.2 \pm 5.1$ & $41.9 \pm 5.3$ & $33.0 \pm 8.6$ & $40.2 \pm 5.1$ & $31.4 \pm 5.8$ \\
\hline \multicolumn{9}{|l|}{ PFFM(\%) } \\
\hline Overall ** & $68.4 \pm 4.7$ & $76.0 \pm 4.5$ & $66.3 \pm 5.0$ & $73.2 \pm 5.0$ & $63.2 \pm 5.9$ & $70.6 \pm 6.6$ & $65.6 \pm 5.7$ & $72.6 \pm 6.6$ \\
\hline Underweight** & $71.1 \pm 6.6$ & $79.6 \pm 5.4$ & $70.5 \pm 5.2$ & $75.6 \pm 8.7$ & $64.9 \pm 7.3$ & $70.7 \pm 8.8$ & $67.6 \pm 7.4$ & $72.8 \pm 8.9$ \\
\hline Normal** & $69.4 \pm 3.7$ & $77.5 \pm 3.6$ & $68.0 \pm 4.4$ & $74.7 \pm 4.5$ & $64.0 \pm 5.2$ & $70.9 \pm 6.3$ & $66.9 \pm 5.2$ & $73.0 \pm 6.0$ \\
\hline Overweight $* *$ & $65.6 \pm 3.8$ & $73.9 \pm 3.6$ & $63.8 \pm 3.8$ & $71.7 \pm 4.4$ & $62.1 \pm 4.8$ & $70.0 \pm 6.0$ & $63.4 \pm 4.4$ & $71.4 \pm 5.1$ \\
\hline Obese* & $63.1 \pm 4.9$ & $69.7 \pm 3.1$ & $59.5 \pm 3.9$ & $68.8 \pm 5.1$ & $58.1 \pm 5.4$ & $67.0 \pm 9.0$ & $59.8 \pm 5.1$ & $68.6 \pm 5.7$ \\
\hline \multicolumn{9}{|l|}{ FMI $\left(\mathrm{kg} / \mathrm{m}^{2}\right)$} \\
\hline Overall** & $7.4 \pm 2.2$ & $5.9 \pm 1.9$ & $8.3 \pm 2.4$ & $6.7 \pm 2.1$ & $8.7 \pm 2.4$ & $6.7 \pm 1.9$ & $8.2 \pm 2.4$ & $6.6 \pm 2.0$ \\
\hline Underweight** & $5.0 \pm 1.1$ & $3.6 \pm 1.1$ & $5.2 \pm 1.0$ & $4.3 \pm 1.6$ & $6.1 \pm 1.3$ & $4.9 \pm 1.4$ & $5.6 \pm 1.3$ & $4.6 \pm 1.5$ \\
\hline Normal** & $6.7 \pm 1.1$ & $4.9 \pm 1.0$ & $7.2 \pm 1.3$ & $5.7 \pm 1.1$ & $8.0 \pm 1.5$ & $6.4 \pm 1.5$ & $7.3 \pm 1.4$ & $6.0 \pm 1.4$ \\
\hline Overweight** & $9.4 \pm 1.3$ & $7.0 \pm 1.0$ & $9.8 \pm 1.3$ & $7.6 \pm 8.0$ & $10.1 \pm 1.4$ & $8.0 \pm 1.6$ & $9.8 \pm 1.3$ & $7.7 \pm 1.4$ \\
\hline Obese* & $12.3 \pm 2.7$ & $9.9 \pm 1.4$ & $13.5 \pm 3.6$ & $10.7 \pm 4.5$ & $13.6 \pm 2.7$ & $10.8 \pm 3.4$ & $13.3 \pm 3.0$ & $10.8 \pm 3.4$ \\
\hline \multicolumn{9}{|l|}{$\operatorname{FFMI}\left(\mathrm{kg} / \mathrm{m}^{2}\right)$} \\
\hline Overall** & $15.7 \pm 2.4$ & $18.1 \pm 2.5$ & $16.0 \pm 1.9$ & $18.1 \pm 2.5$ & $14.7 \pm 2.4$ & $16.0 \pm 2.7$ & $15.4 \pm 2.3$ & $17.0 \pm 2.8$ \\
\hline Underweight** & $12.4 \pm 1.3$ & $13.9 \pm 0.8$ & $12.4 \pm 0.8$ & $13.3 \pm 1.6$ & $11.2 \pm 1.3$ & $12.1 \pm 1.9$ & $11.7 \pm 1.4$ & $12.5 \pm 1.8$ \\
\hline Normal** & $15.1 \pm 1.3$ & $17.0 \pm 1.4$ & $15.2 \pm 1.2$ & $16.9 \pm 1.5$ & $14.1 \pm 1.6$ & $15.5 \pm 1.8$ & $14.8 \pm 1.4$ & $16.1 \pm 1.8$ \\
\hline Overweight** & $17.8 \pm 1.2$ & $19.7 \pm 1.4$ & $17.2 \pm 1.1$ & $19.3 \pm 1.4$ & $16.6 \pm 1.5$ & $18.7 \pm 1.9$ & $17.1 \pm 1.3$ & $19.2 \pm 1.6$ \\
\hline Obese* & $20.8 \pm 1.9$ & $22.7 \pm 1.3$ & $19.6 \pm 2.2$ & $22.9 \pm 2.9$ & $18.7 \pm 1.5$ & $21.8 \pm 2.7$ & $19.5 \pm 2.0$ & $22.6 \pm 2.5$ \\
\hline \multicolumn{9}{|l|}{ PFMR } \\
\hline Overall** & $1.4 \pm 0.2$ & $1.0 \pm 0.2$ & $1.4 \pm 0.2$ & $\mathrm{I} . \mathrm{I} \pm 0.2$ & $1.6 \pm 0.3$ & $1.3 \pm 0.4$ & $1.5 \pm 0.3$ & $1.2 \pm 0.3$ \\
\hline Underweight** & $1.7 \pm 0.4$ & $1.2 \pm 0.3$ & $1.7 \pm 0.3$ & $1.4 \pm 0.5$ & $2.0 \pm 0.4$ & $1.7 \pm 0.6$ & $1.9 \pm 0.4$ & $1.6 \pm 0.6$ \\
\hline Normal** & $1.4 \pm 0.2$ & $1.0 \pm 0.2$ & $1.4 \pm 0.2$ & $1.1 \pm 0.2$ & $1.6 \pm 0.3$ & $1.3 \pm 0.3$ & $1.5 \pm 0.2$ & $1.2 \pm 0.3$ \\
\hline Overweight** & $1.3 \pm 0.1$ & $1.0 \pm 0.1$ & $1.3 \pm 0.1$ & $1.0 \pm 0.2$ & $1.4 \pm 0.2$ & $1.1 \pm 0.2$ & $1.4 \pm 0.2$ & $1.1 \pm 0.2$ \\
\hline Obese* & $1.1 \pm 0.1$ & $0.9 \pm 0.1$ & $1.2 \pm 0.1$ & $0.9 \pm 0.1$ & $1.3 \pm 0.1$ & $1.0 \pm 0.2$ & $1.2 \pm 0.1$ & $1.0 \pm 0.1$ \\
\hline \multicolumn{9}{|l|}{ PFFMR } \\
\hline Overall** & $3.1 \pm 0.6$ & $3.3 \pm 0.7$ & $2.8 \pm 0.5$ & $3.0 \pm 0.5$ & $2.8 \pm 0.6$ & $3.2 \pm 0.6$ & $2.9 \pm 0.6$ & $3.1 \pm 0.6$ \\
\hline Underweight* & $4.1 \pm 0.4$ & $4.6 \pm 0.4$ & $4.0 \pm 0.4$ & $4.3 \pm 0.6$ & $3.8 \pm 0.5$ & $4.2 \pm 0.5$ & $3.9 \pm 0.5$ & $4.2 \pm 0.5$ \\
\hline Normal** & $3.2 \pm 0.3$ & $3.6 \pm 0.4$ & $3.1 \pm 0.3$ & $3.3 \pm 0.3$ & $2.9 \pm 0.4$ & $3.3 \pm 0.4$ & $3.0 \pm 0.4$ & $3.3 \pm 0.4$ \\
\hline Overweight** & $2.4 \pm 0.2$ & $2.7 \pm 0.2$ & $2.4 \pm 0.2$ & $2.7 \pm 0.2$ & $2.3 \pm 0.2$ & $1.9 \pm 0.3$ & $2.4 \pm 0.2$ & $2.6 \pm 0.2$ \\
\hline Obese & $1.9 \pm 0.3$ & $2.1 \pm 0.2$ & $1.8 \pm 0.3$ & $2.1 \pm 0.3$ & $1.8 \pm 0.2$ & $2.1 \pm 0.3$ & $1.8 \pm 0.3$ & $2.1 \pm 0.3$ \\
\hline
\end{tabular}

Notes: $* P<0.05$ only in females; $* * P<0.05$ in both males and females.

Abbreviations: FM, fat mass; FFM, fat free mass; PFM, percentage of fat mass; PFFM, percentage fat free mass; FMI, fat mass index; FFMl, fat free mass index, PFMR, percentage fat mass to BMI ratio; PFFMR, percentage fat free mass to BMI ratio. 


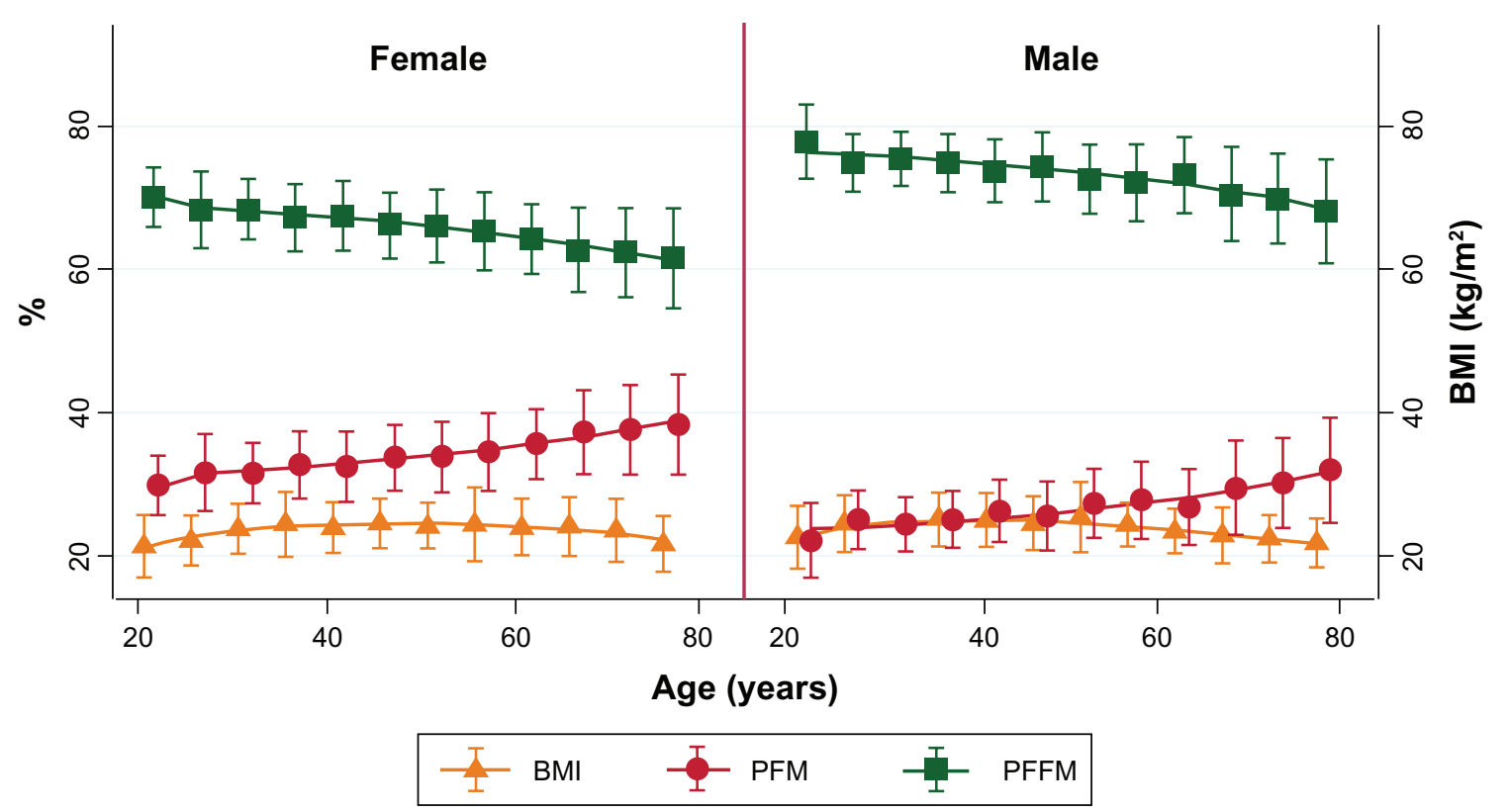

Figure I Relationship of BMI, percentage body fat, and percentage lean body mass demonstrated by mean \pm standard deviation over age in each gender. Abbreviations: BMI, body mass index; PFM, percentage of fat mass; PFFM, percentage of fat free mass.

plot in Figure 4. The predicted error line in these two curves revealed that underestimation might occur in older people using calculated PFM prediction by BMI results.

When taking into account age group, gender, and ethnicity difference, one multinational study of a Japanese-based population suggested that the PFM in that population was associated with a BMI of $>30$ (obesity diagnosis according to BMI criteria). The results for males and females were PFM (Asian criteria) of 28-29 and 40-41, respectively. ${ }^{9}$ However, the cutoff point for determining obesity was different from the previous Thai adults study, where obesity was defined using PFM (Thai criteria) cutoff points of 25 for males and 35 for females. ${ }^{10}$ Using the BMI status definition for obesity diagnosis in this study, the lower cutoff point of PFM

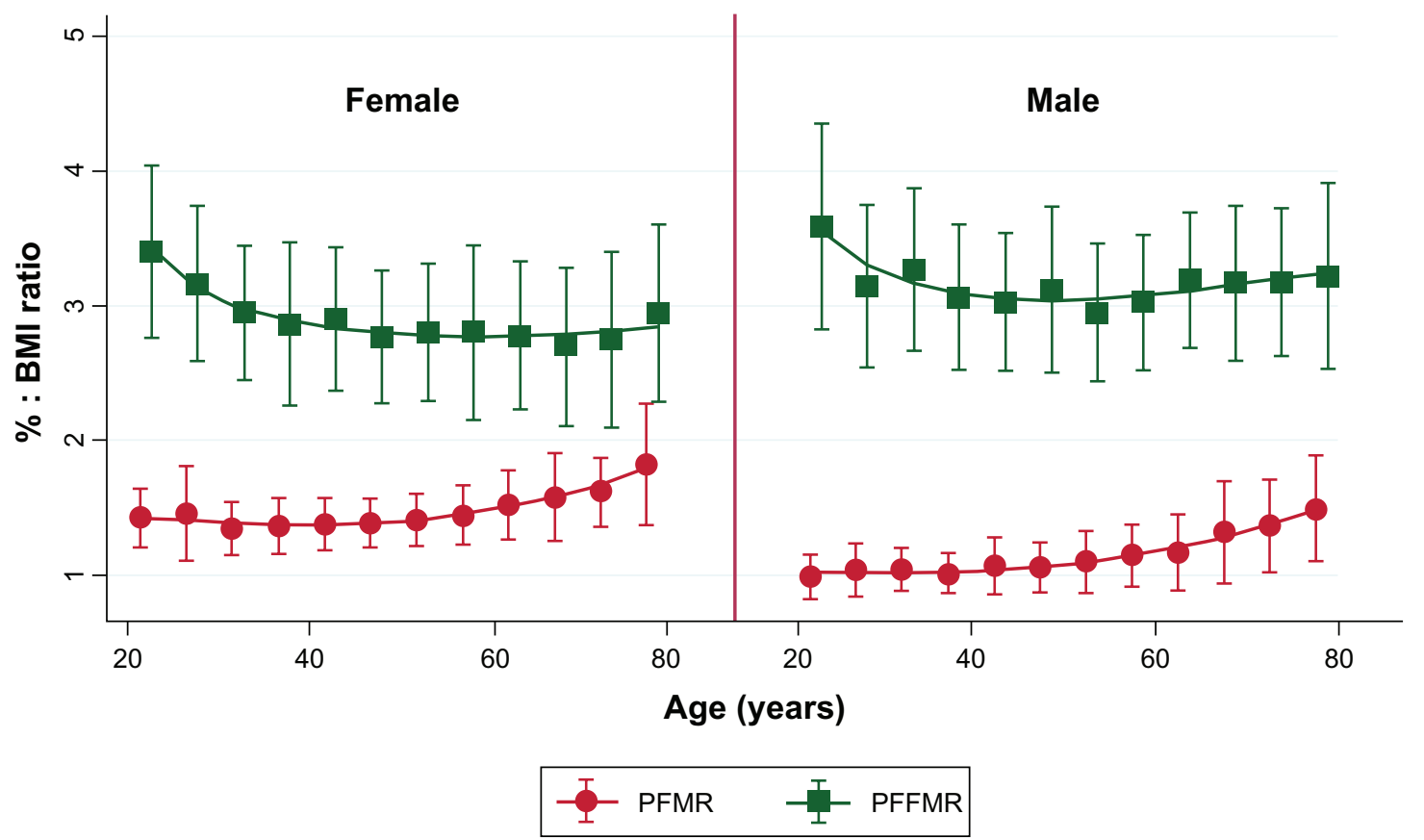

Figure 2 Relationship of PFMR with PFFMR demonstrated by mean \pm standard deviation over age in each gender. Abbreviations: PFMR, percentage of fat mass to BMI ratio; PFFMR, percentage of fat free mass to BMI ratio. 
Table 3 Multivariate regression coefficient of parameters associated with percentage fat mass measured by bioelectrical impedance analysis

\begin{tabular}{|c|c|c|c|c|c|c|c|c|}
\hline Parameters & Younger $^{\dagger}$ & $P$ & Middle $^{\dagger}$ & $P$ & Older ${ }^{\dagger}$ & $P$ & Total $^{\dagger}$ & $P$ \\
\hline Female & $\begin{array}{l}7.92 \\
(7.14 / 8.69)\end{array}$ & $<0.01$ & $\begin{array}{l}7.41 \\
(6.83 / 7.98)\end{array}$ & $<0.01$ & $\begin{array}{l}7.61 \\
(6.88 / 8.35)\end{array}$ & $<0.01$ & $\begin{array}{l}7.44 \\
(7.02 / 7.85)\end{array}$ & $<0.01$ \\
\hline Age (year) & $\begin{array}{l}0.07 \\
(0.01 / 0.12)\end{array}$ & 0.02 & $\begin{array}{l}0.13 \\
(0.08 / 0.18)\end{array}$ & $<0.01$ & $\begin{array}{l}0.26 \\
(0.21 / 0.31)\end{array}$ & $<0.01$ & $\begin{array}{l}0.15 \\
(0.14 / 0.17)\end{array}$ & $<0.01$ \\
\hline BMI & $\begin{array}{l}0.57 \\
(0.48 / 0.66)\end{array}$ & $<0.01$ & $\begin{array}{l}0.66 \\
(0.59 / 0.74)\end{array}$ & $<0.01$ & $\begin{array}{l}0.42 \\
(0.32 / 0.52)\end{array}$ & $<0.01$ & $\begin{array}{l}0.50 \\
(0.45 / 0.55)\end{array}$ & $<0.01$ \\
\hline Underweight ${ }^{\ddagger}$ & $\begin{array}{l}-1.4 \mid \\
(-0.06 /-2.77)\end{array}$ & 0.04 & $\begin{array}{l}-2.29 \\
(-4.05 /-0.53)\end{array}$ & 0.11 & $\begin{array}{l}-1.46 \\
(-2.72 /-0.20)\end{array}$ & 0.02 & $\begin{array}{l}-1.04 \\
(-1.86 /-0.22)\end{array}$ & 0.13 \\
\hline Overweight ${ }^{\ddagger}$ & $\begin{array}{l}3.48 \\
(2.54 / 4.42)\end{array}$ & $<0.01$ & $\begin{array}{l}3.68 \\
(3.04 / 4.32)\end{array}$ & $<0.01$ & $\begin{array}{l}1.85 \\
(0.93 / 2.78)\end{array}$ & $<0.01$ & $\begin{array}{l}2.75 \\
(2.26 / 3.24)\end{array}$ & $<0.0$ I \\
\hline Obese $^{\ddagger}$ & $\begin{array}{l}6.59 \\
(5.19 / 8.00)\end{array}$ & $<0.01$ & $\begin{array}{l}7.50 \\
(6.28 / 8.7 I)\end{array}$ & $<0.01$ & $\begin{array}{l}5.68 \\
(4.02 / 7.32)\end{array}$ & $<0.01$ & $\begin{array}{l}6.48 \\
(5.62 / 7.35)\end{array}$ & $<0.01$ \\
\hline
\end{tabular}

Notes: ${ }^{\dagger}$ Regression coefficient ( $95 \%$ confidence interval: lower/upper value); ${ }^{\ddagger}$ compared with normal status as reference.

Abbreviations: BMI, body mass index; BIA, bioelectrical impedance analysis.

Thai criteria was reasonable for obesity classification as it gave less false negative rates of obesity diagnosis (Asian vs Thai criteria; $47.4 \%$ [46/97] vs 7.22\% [7/97] in females and $21.28 \%$ [10/47] vs $8.51 \%$ [4/47] in males).

\section{Discussion}

The authors stratified weight status into four groups based on previous studies. ${ }^{9,15}$ In Table 1 the average body weight, height, and BMI were significantly different between age groups. However, the sample in this study is not a representative sample of the overall proportion of the population by weight status in Thailand: nearly $60 \%$ of the volunteers had a normal weight status, $25 \%$ were overweight, and $<10 \%$ were in the extreme weight status groups (underweight or obese). However, referral or sampling bias from the selection process might be of concern due to the enrollment site being a tertiary hospital. Although each weight status classified by BMI was not a prospective cohort, the BMI was an indicator of mortality risk. ${ }^{11}$ In addition, BMI changed according to variations in body fat. ${ }^{2,16}$ The BMI criteria were also used for weight status classification. However, the criteria may have been subject to spectrum bias when they were compared with the body fat measurement criteria. ${ }^{15,16}$ Because of these reasons, consideration of both $\mathrm{BMI}$ and fat mass together in each gender and by ethnicity might be more precise when predicting death as well as when diagnosing obesity.

The standard ways of measuring FM and FFM need special investigation. Five commonly used methods for body fat detection as standard references are: body density via underwater weighing, DXA, three- and fourcompartment models, deuterium dilution techniques, and bioelectrical impedance. ${ }^{9,10,17,18}$ Along with the limitations to determining body fat, there are many proposed formulas for the calculation of percentage of body fat that use basic anthropometric parameters (BMI, age, gender, and ethnic differences). These generated prediction formulas are based on previously devised standard measurements; $9,10,19,20$ they have differences in coefficients regarding age, gender, and ethnic differences. However, gender and ethnicity were categorized data, while age was a continuous variable. In addition, the predictive coefficient of age in these formulas use constant values throughout the life span in the same ethnic group, ${ }^{3,9,10,19}$ which may have distorted and produced prediction errors from different spectrums in the age groups

Table 4 Coefficient alteration between age group quarters adjusted by gender and BMI

\begin{tabular}{|c|c|c|c|c|}
\hline Parameter & $<60$ years $^{\dagger}$ & $\geq 60$ years $^{\dagger}$ & Difference $^{\dagger}$ & $P$ value \\
\hline PFM & $0.09(0.07 / 0.1 \mathrm{I})$ & $0.26(0.2 \mathrm{I} / 0.3 \mathrm{I})$ & $0.18(0.13 / 0.23)$ & $<0.01$ \\
\hline PFFM & $-0.09(-0.1 \mathrm{I} /-0.07)$ & $-0.26(-0.3 \mathrm{I} /-0.2 \mathrm{I})$ & $-0.18(-0.23 /-0.13)$ & $<0.01$ \\
\hline FMI & $0.02(0.01 / 0.02)$ & $0.06(0.05 / 0.07)$ & $0.04(0.03 / 0.06)$ & $<0.01$ \\
\hline FFMI & $-0.02(-0.02 /-0.01)$ & $-0.06(-0.07 /-0.05)$ & $-0.05(-0.06 /-0.03)$ & $<0.01$ \\
\hline PFMR $\left(\times 10^{-2}\right)$ & $0.32(0.23 / 0.4 I)$ & $1.20(0.95 / 1.46)$ & $0.97(0.73 / 1.21)$ & $<0.01$ \\
\hline PFFMR $\left(\times 10^{-2}\right)$ & $-0.6 \mathrm{I}(-0.73 /-0.49)$ & $-0.87(-1.13 /-0.60)$ & $-0.22(-0.49 / 0.04)$ & 0.11 \\
\hline
\end{tabular}

Note: ${ }^{\dagger}$ Regression coefficient ( $95 \%$ confidence interval: lower/upper value).

Abbreviations: PFM, Percentage of fat mass; PFFM, Percentage fat free mass; FMI, Fat mass index; FFMI, Fat free mass index; PFMR, Percentage fat mass to BMI ratio; PFFMR, Percentage fat free mass to BMI ratio. 


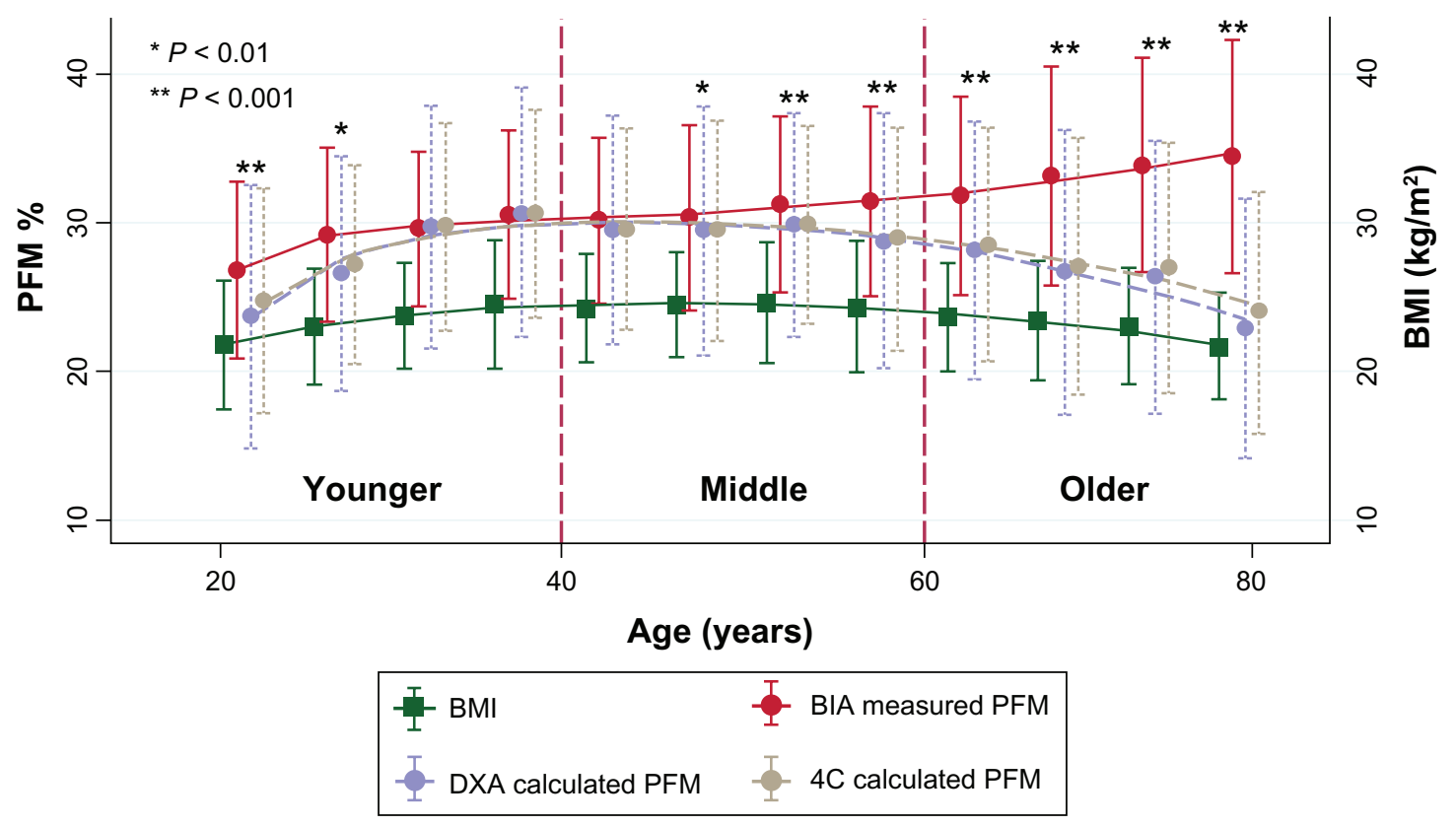

Figure 3 Comparing measured BIA, calculated PFM and BMI demonstrated by mean \pm SD in each age group.

Abbreviations: BMI, body mass index; BIA, bioelectrical impedance analysis; PFM, percentage of fat mass; DXA, dual energy X-ray absorptiometry; 4C, four-compartment method; SD, standard deviation.

due to biological distinctions in metabolic synthesis in older people. ${ }^{21}$ These hypotheses were confirmed in this study, and the age spectrum played an important role in fat mass. To reduce the interaction of BMI differences in each age group in this study, stratified weight status and gender were analyzed (shown in Table 2 with mean percentage body fat for each). Of these, there were significant differences in PFM and PFFM as well as FMI and FFMI at the same weight status for both males and females, except in the obese volunteers, where age showed a reduced influence in females.

The definition of the percentage of body fat for obesity classification is controversial. ${ }^{9} 10$ However, in this study the obesity PFM cutoff points of 25 for males and 35 for females had a lower false negative rate than PFMs of 28 and 40, respectively. The changes in PFM, PFFM, and BMI are shown in Figure 1. With increasing age, BMI and PFM diverged, especially in older volunteers. These contrasted with PFFM, which decreased in parallel with the BMI. To confirm these variables with the age spectrums, multivariate analysis (shown in Table 3) was performed, and this revealed an increased age coefficient in older volunteers. To verify the alteration of the coefficient, the authors analyzed PFMR and PFFMR against age change, as shown in Figure 2. The age spectrum effected significant differences in all of the FM and FFM variables except the PFFMR. This might be explained by the increase of PFM concurrent with the slightly decreasing PFFM caused by the physiological alterations of aging. ${ }^{19}$
The authors demonstrated an error of formula for estimating the PFM in terms of constant coefficient of age compared with measured body fat by BIA in Figures 3 and 4 . The overall difference was comparable in the younger and middle-aged groups, but the graph began to diverge at 50 years of age, with the difference increasing as age increased. In all of the findings in this study, the formula predicted that the PFM should be stratified in each age group with different coefficients.

There were a number of potential strengths and weaknesses in this study. The major strength was a large sample size when compared with previous studies and this study's samples were distributed across all groups of weight status in each subgroup. Also, the bioelectrical impedance analyzer is noninvasive, portable, and is reported to have acceptable validity and accuracy. ${ }^{22}$ It is widely used in Thailand due to being an inexpensive and portable instrument. However, the criterion validity using the Biodynamics BIA $310 \mathrm{e}$ is unknown for Thai people, and the authors noticed a wide range of measurement error if the researcher did not adhere strictly to the examination guidelines. Therefore, thorough checking of the location of the electrocardiograph pads had to be performed and strict following of screening pretest protocols needed to be verified before performing the measurements.

There were a number of inevitable limitations to the study. First, measurement error could occur for some volunteers who did not fully follow the strict pretest preparation. Second, 

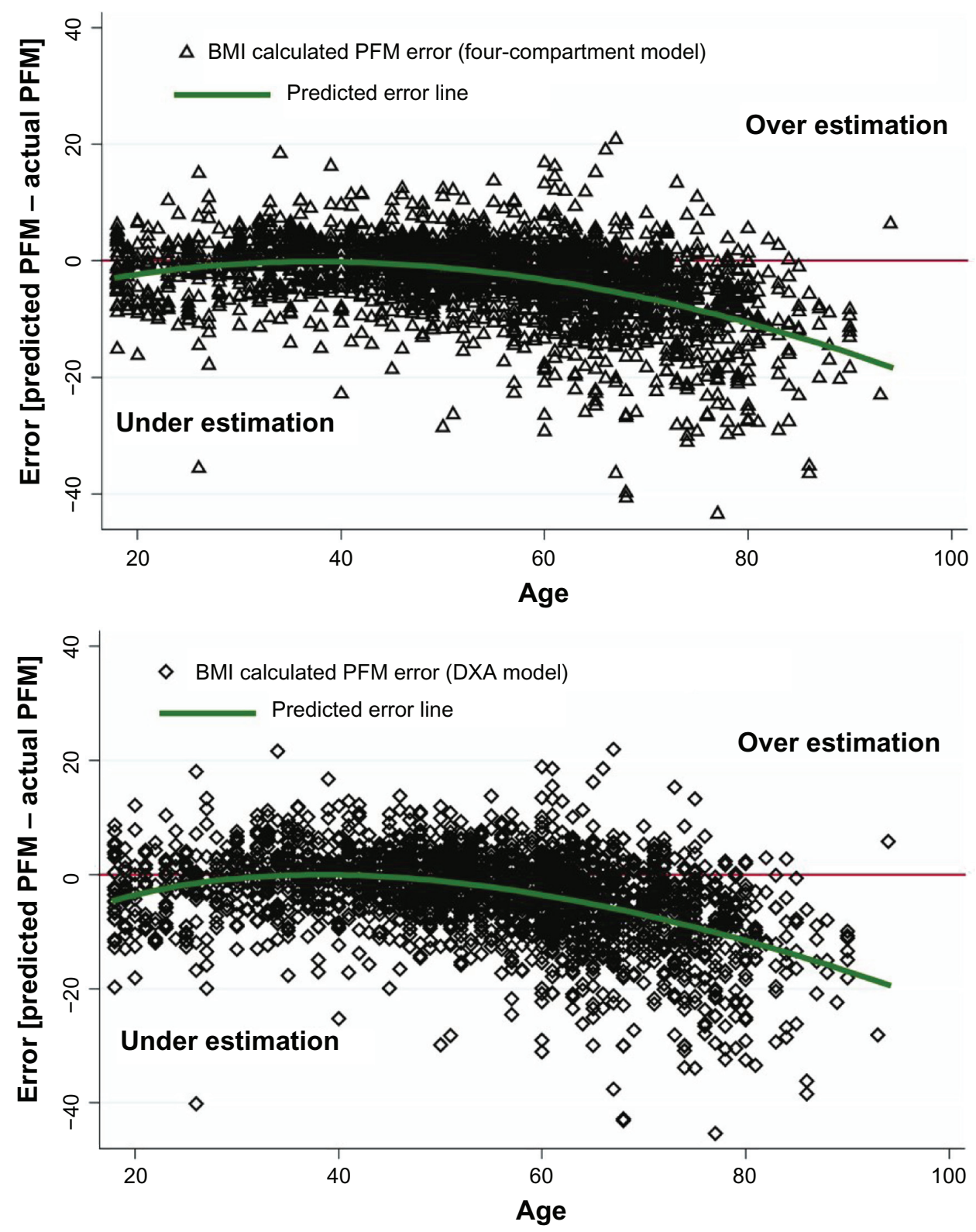

Figure 4 Bland-Altman plot demonstrated error of PFM prediction using BMI in four compartment and DXA model over age. Abbreviations: BMI, body mass index; PFM, percentage of fat mass; DXA, dual energy X-ray absorptiometry.

nearly $96 \%$ of the volunteers lived in the northern region of Thailand. Even though there are similarities in body type and environment across most rural areas in Thailand, extrapolating these results to other populations should be done with caution due to the differences in lifestyles and eating patterns in each population. Third, the method for screening volunteers was by interview. Some of the volunteers, especially older patients, may have had an unknown health history, such as undetected disease, which may have resulted in selection errors. Fourth, the authors could not control for the volunteers' occupations, which might have changed throughout their lives. There may have been differences in the amount of vigorous physical activity they engaged in due to their occupation, which may have changed their body composition, but this was not measured in this study. However, it should be noted that none of the volunteers included in the present study were athletes or body builders. Finally, the authors compared measurement results using the BIA to formulas that were created by the DXA and four-compartment methods. Using a different method might have yielded distinctly different results; however, the authors observed that the correlation of measured and calculated PFM intersected in younger volunteers and this might explain the validity of the formula difference in each age spectrum. 


\section{Conclusion}

The relationship between PFM and BMI shows variation on the age spectrum. A calculated formula in older people might be distorted with the utilization of constant coefficients throughout the life span. Therefore, it is concluded that older people should be considered a special population and a prediction formula should be performed separately.

\section{Acknowledgments}

This study was supported by the Medical Association of Thailand (Prasert Prasarttong-osoth) Research Fund. The authors gratefully thank the Surgical Outpatient Department and Hospital Registration Unit, Faculty of Medicine, Maharaj Nakorn Chiang Mai Hospital, Chiang Mai University, Chiang Mai, Thailand, for providing rooms and assistance.

\section{Disclosure}

The authors have no conflicts of interest in this work. This study was a part of Assistant Professor Kaweesak Chittawatanarat's $\mathrm{PhD}$ thesis project in clinical epidemiology.

\section{References}

1. Calle EE, Thun MJ, Petrelli JM, Rodriguez C, Heath CW Jr. Body-mass index and mortality in a prospective cohort of US adults. $N$ Engl J Med. 1999;341(15):1097-1105.

2. Goh VH, Tain CF, Tong TY, Mok HP, Wong MT. Are BMI and other anthropometric measures appropriate as indices for obesity? A study in an Asian population. J Lipid Res. 2004;45(10):1892-1898.

3. Deurenberg P, Keyou G, Hautvast JG, Jungzhong W. Body mass index as predictor for body fat: comparison bebetween Chinese and Dutch adult subjects. Asia Pacific J Clin Nutr. 1997;6(2):102-105.

4. Deurenberg P, Yap M, van Staveren WA. Body mass index and percent body fat: a meta analysis among different ethnic groups. Int J Obes Relat Metab Disord. 1998;22(12):1164-1171.

5. Allison DB, Zhu SK, Plankey M, Faith MS, Heo M. Differential associations of body mass index and adiposity with all-cause mortality among men in the first and second National Health and Nutrition Examination Surveys (NHANES I and NHANES II) follow-up studies. Int $J$ Obes Relat Metab Disord. 2002;26(3):410-416.

6. Zhu S, Heo M, Plankey M, Faith MS, Allison DB. Associations of body mass index and anthropometric indicators of fat mass and fat free mass with all-cause mortality among women in the first and second National Health and Nutrition Examination Surveys follow-up studies. Ann Epidemiol. 2003;13(4):286-293.
7. Tremblay A, Bandi V. Impact of body mass index on outcomes following critical care. Chest. 2003;123(4):1202-1207.

8. Mullen JT, Moorman DW, Davenport DL. The obesity paradox: body mass index and outcomes in patients undergoing nonbariatric general surgery. Ann Surg. 2009;250(1):166-172.

9. Gallagher D, Heymsfield SB, Heo M, Jebb SA, Murgatroyd PR, Sakamoto Y. Healthy percentage body fat ranges: an approach for developing guidelines based on body mass index. Am J Clin Nutr. 2000; 72(3):694-701.

10. Pongchaiyakul C, Kosulwat V, Rojroongwasinkul N, et al. Prediction of percentage body fat in rural Thai population using simple anthropometric measurements. Obes Res. Apr 2005;13(4):729-738.

11. Wang J, Thornton JC, Russell M, Burastero S, Heymsfield S, Pierson RN Jr. Asians have lower body mass index (BMI) but higher percent body fat than do whites: comparisons of anthropometric measurements. Am J Clin Nutr. 1994;60(1):23-28.

12. Wang J, Deurenberg P. The validity of predicted body composition in Chinese adults from anthropometry and bioelectrical impedance in comparison with densitometry. Br J Nutr. 1996;76(2):175-182.

13. Kyle UG, Bosaeus I, De Lorenzo AD, et al. Bioelectrical impedance analysis - Part I: review of principles and methods. Clin Nutr. 2004; 23(5):1226-1243.

14. Gudivaka R, Schoeller DA, Kushner RF, Bolt MJ. Single- and multifrequency models for bioelectrical impedance analysis of body water compartments. J Appl Physiol. 1999;87(3):1087-1096.

15. World Health Organization. Physical status: the use and interpretation of anthropometry. Report of a WHO Expert Committee. World Health Organ Tech Rep Ser. 1995;854:1-452.

16. Curtin F, Morabia A, Pichard C, Slosman DO. Body mass index compared to dual-energy $\mathrm{x}$-ray absorptiometry: evidence for a spectrum bias. J Clin Epidemiol. 1997;50(7):837-843.

17. Lanham DA, Stead MA, Tsang K, Davies PS. The prediction of body composition in Chinese Australian females. Int J Obes Relat Metab Disord. 2001;25(2):286-291.

18. Svendsen OL, Haarbo J, Hassager C, Christiansen C. Accuracy of measurements of body composition by dual-energy x-ray absorptiometry in vivo. Am J Clin Nutr. 1993;57(5):605-608.

19. Deurenberg P, Weststrate JA, Seidell JC. Body mass index as a measure of body fatness: age- and sex-specific prediction formulas. Br J Nutr. 1991;65(2):105-114.

20. Katch FI, McArdle WD. Prediction of body density from simple anthropometric measurements in college-age men and women. Hum Biol. 1973;45(3):445-455.

21. Volpi E, Mittendorfer B, Rasmussen BB, Wolfe RR. The response of muscle protein anabolism to combined hyperaminoacidemia and glucose-induced hyperinsulinemia is impaired in the elderly. $J$ Clin Endocrinol Metab. 2000;85(12):4481-4490.

22. Demura S, Yamaji S, Goshi F, Kobayashi H, Sato S, Nagasawa Y. The validity and reliability of relative body fat estimates and the construction of new prediction equations for young Japanese adult males. $J$ Sports Sci. 2002;20(2):153-164.
Clinical Interventions in Aging

\section{Publish your work in this journal}

Clinical Interventions in Aging is an international, peer-reviewed journal focusing on evidence-based reports on the value or lack thereof of treatments intended to prevent or delay the onset of maladaptive correlates of aging in human beings. This journal is indexed on PubMed Central, MedLine, the American Chemical Society's 'Chemical Abstracts

\section{Dovepress}

Service' (CAS), Scopus and the Elsevier Bibliographic databases. The manuscript management system is completely online and includes a very quick and fair peer-review system, which is all easy to use. Visit $\mathrm{http}: / / \mathrm{www}$.dovepress.com/testimonials.php to read real quotes from published authors. 